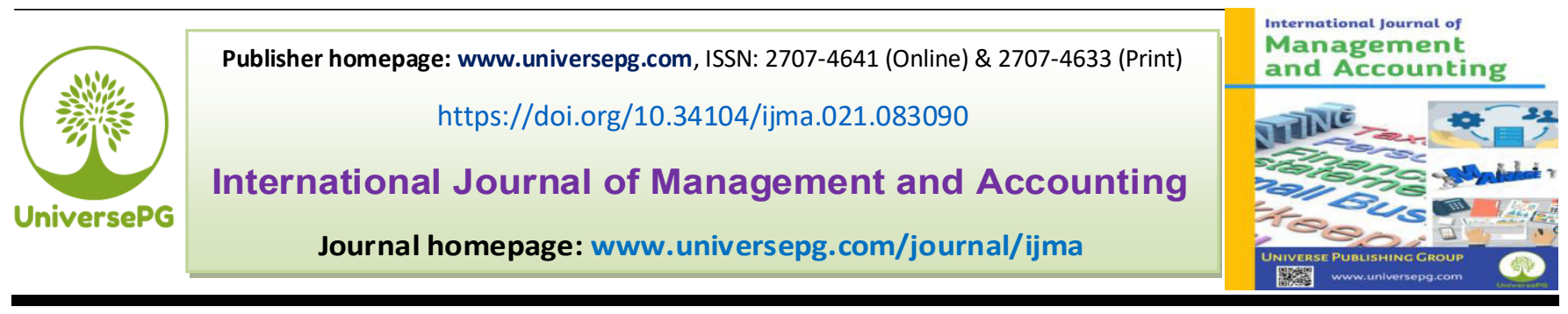

\title{
Portfolio Construction Using Financial Ratio Indicators and Classification through Machine Learning
}

\section{Hasan M Sami*}

School of Business, Canadian University Bangladesh, Dhaka, Bangladesh.

*Correspondence: hasan.sami21@yahoo.com (Hasan M Sami, Senior Lecturer, School of Business, Canadian University Bangladesh, Dhaka, Bangladesh).

\begin{abstract}
Financial Ratios have been a major indicator for financial asset selection. It's seen that the decision taken to construct a portfolio based on financial ratio indicators has been able to make better returns than the random asset allocation process in the portfolio. This research will show multiple classifications based on unsupervised machine learning processes to satisfactorily determine investable assets or securities for portfolio contribution. Our suggested portfolio would then be compared with a random portfolio for a specific time frame in order to determine portfolio return, Sharpe ratio, and portfolio performance.
\end{abstract}

Keywords: Means clustering, Neighbor algorithm, Current ratio, Portfolio optimization, and Markowitz theory.

\section{INTRODUCTION:}

Financial performance optimization has been a major concern for most investors and market analysts. It's seen that investment management process is highly dependent on investment policy, market timing and security selection (Brinson et al., 1986). For the purpose of solving the research perspective our concern of management would associate with security selection. Brinson et al. (1986) also mentions that an effective investment policy would be dependent on these three factors, but in process of understanding the quailfication of well-judged financial ratio indicators for assets, our comparison with randomized port-folio's would be compared with portfolio's created by assets suggested by financial ratio indicators classified upon Machine Learning processes (Azam et al., 2020).

Primary concern of portfolio construction is risk minimization through diversification of assets in a portfolio (Nanda et al., 2010). This research would involve itself with selection of assets based on suggesUniversePG I www.universepg.com tive financial ratio indicators. Through the suggestive assets our target would be construct a portfolio and check its return options for a given time period. Nanda et al. (2010) have found that, through K Means Clustering we have been able to identify more specific asset classes rather than SOM or Fuzzy C-Means Clustering process. This research would also compare the portfolio risk measurement with market benchmark index.

It's seen that sustainable economic growth and development of social market plays an important role for financial markets and asset performance (Khan et al., 2020). Khan et al. (2020) suggested that through studying various key features such as skewness, kurtosis, symmetry and fat tail risk portfolio optimization could be estimated through weighted allocation of assets. In this research process, the key feature also includes minimum investment contribution for sustainable growth, but our comparison needs to be justified with smaller investment and educated asset choices 
rather than random asset choices and indefinite contribution for assets. It's observed that rather than institutional investors in case of smaller investors, the considered standard deviation does not go beyond a prescribed risk level (Baumann et al., 2012).

As Machine Learning undertakes an approach to classify assets on the basis of defined educated criteria in reference to the considered financial ratios, it's highly imperative that the classification methods need to be unbiased and solution centric based on situational factors (Li et al., 2014). As Barnes suggests that in order to understand the key situational constraints of a firm, all the key financial ratio's needs to be understood (Barnes, 1987) hence asset allocation decision making needs to be dependent on financial ratios of assets. It's also seen that financial ratio indicators remain as key factors to specifically identify assets or securities to prohibit bad investments (Lin et al., 2011). Hence the primary research concern that gets developed through this process is:

a) Are Machine Learning approaches useful for selection of assets based on classification through financial ratios?

b) Can Portfolio Optimizations be achieved on the basis of evaluations of selected assets?

\section{Literature Review}

It's been observed that various financial ratios play different roles in order to exhibit financial conditions of an organization in different conditions. Chen \& Shimerda (Chen et al., 1981) explains the importance of financial ratios as whole in order to determine overall condition of a company. Jordan et al, (2007) have evidenced that EPS is by far the most important financial ratio that determines the importance of selection of an asset for financial decision making. Through various research prospects it's also seen that EPS plays a vital role for company's future prospect (Rashidi et al., 2007). It's observed that firm's liquidity capability is a strong indicator in terms financial standing and further financial investments. In terms considering important constituents for portfolio construction, it found that investment is highly based on ratio analysis processes (Brinson et al., 1986). Sustainability is a method of suggestion generated by portfolio construction and risk management process for the highest possible return (Khan et al., 2020). In cases of UniversePG I www.universepg.com online portfolio formation Baumann et al. (2012); Li et al. (2014) as the investors are mostly making smaller investment hence the risk allocation is different in comparison to institutional investors.

Current Ratio is considered as another important ratio that submits the liquidity of any organization. It's found that in operational level (industry level) a firm considers to measure importance in relation to profit (Eljeily, 2004) with cash conversion and availability. It's observed that although the relationship between investments in current assets and liability are a major indicator for firms financial standing (Qudah et al., 2015), its observed that a moderate policy of following a good current ratio always makes a favorable decision.

As Nanda et al. (2010) have successfully suggested the importance of clustering as a financial benchmark for segregating different class of assets for performance analysis, Momeni et al. (2015) have proved how the decision of selecting a good class of assets can make ultimate benefits. Abhishek \& Samidha, (2017) found beneficial result through clustering method for segregating stocks in terms of performance measures for Shanghai Stock Exchange. Hence, in our research process we are considering $\mathrm{K}$ Means Clustering an important and derivative technique for Stock selection and portfolio formation.

Alkhatib et al. (2018) have found that in case of prediction-based systems, K Nearest Neighbor algorithm has the lowest error margin and most rational results with highest similarity with predicted results. Bauman \& Miller, (1997) have suggested that continuously favorable EPS value plays an important role for a company's financial future. In order to make our research process successful enough we would initiate the suggestion of best EPS and Current ratio value suggested by market index review for financial decisionmaking processes.

As Martin Suggested that (Robert, 2021) through programming language-based portfolio optimizer PyPortfolioOpt uses all sectors of risk return parity measurements in a favorable account through mean variance allocation, Black-Litterman allocation (Idjorek, 2007) and machine learning inspired Hierarchical Risk Parity Algorithm (Lopez, 2016), hence the results 
obtained through PyPortfolio optimization processes could be beneficial for research and portfolio performance evaluation purposes.

In accordance to Saito in Investor Business (Saito, 2021), a company with more than $25 \%$ EPS value in comparison to previous years data is found to be in strong demand. It's also seen that the higher the EPS value the better is the company's indication of overall stock price increase is there in future (Lopez, 2016). Similarly, its seen that a company with having a better than one 1 current ratio is supposed to have more liquidities in comparison to companies which have less than 1 current ratio (Saito, 2021). In suggestion it found that any companies which have current ratio in between 1.2 to 2 perform right at its best in terms of liquidation (Saito, 2021).

Finally in reference to portfolio return and risk measure a company needs to evaluate. The overall measure of Sharpe ratio Bodnar et al. (2016); Geltner, (2003) and MFoxCNBC, (2020) has led benefits for overall portfolio risk and return measure in a profitable manner. Furthermore, it's seen selection of investment in a specific time period is of paramount importance in order to understand portfolio quality (Zhou, 2000).

\section{Theoretical Framework}

Importance of Financial Ratios - Chen \& Shimerda, (1981) have found that key financial ratios are the most important determinant of organizational health. It found that -

a) They are used to evaluate key warning signs for any operating cycle.

b) They are highly industry specific indicators of organizational performance measurements.

c) It's a measurement tool that compares one company with the industry and other companies of industry.

EPS - As Jordan et al. (2007) have suggested that EPS is one of the key indicators of an organization in terms of its performance measures. In accordance to CFI, how much each share is earns in respect of any situational constraint is represented through EPS hence under general rule, higher value of EPS the better the company is performing and lowers EPS shows a lower performance.
Earnings Per Share Formula

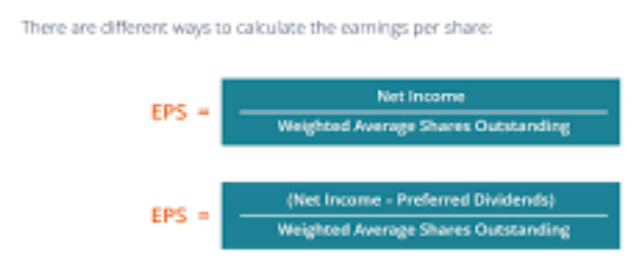

Current Ratio - Eljelly suggested (Eljeily, 2004) that current ratio basically shows how much current liabilities a company own in comparison to how much current assets the company possess under any given period of time. In general, the higher the ratio of current assets divided by current liabilities the better the performance of the assets.

\section{Current Ratio}

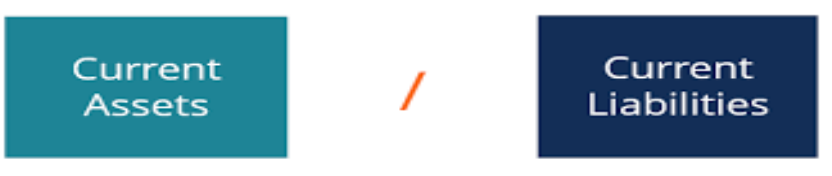

Importance of Portfolio Optimization - Portfolio management is the art of selecting the right investment tools in the right proportion to generate optimum returns with a balance of risk from the investment made in accordance to Bauman et al. (1997). In order to successfully implement portfolio optimization through PyPortfolio Optimizer it's seen that an optimum portfolio can reduce the diversifiable risk till zero (López, 2016).

\section{Portfolio Return Formula

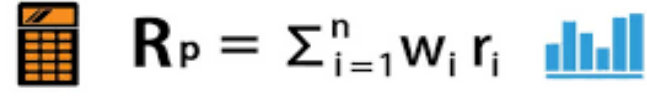

As the Portfolio consists of Assets of various weights with each having different return capability, hence the overall portfolio will have the capability of return in comparison to defined weight allocations to different assets which will be assigned in terms of their expected returns, the overall return of all these assets will be the complete return of the portfolio. 
Sharpe Ratio - Sharpe Ratio: The Sharpe Proportion may bea budgetary metric frequently utilized by speculators when surveying the execution of speculation administration items and experts. It comprises of taking the abundance return of the portfolio, relative to the risk-free rate, and separating it by the standard deviation of the portfolio's abundance returns (Bodnar et al., 2016). A great Sharpe proportion will have values more noteworthy than or rise to 1.00 which is by and large considered "good", as this would propose that the portfolio is advertising abundance returns relative to its instability (Dowd, 2000). Financial specialists will regularly compare (Dowd, 2000) the Sharpe Proportion of a portfolio relative to its peers. A portfolio with a Sharpe Proportion of 1.00 may well be considered lacking on the off chance that the competitors in its peer gather have a normal Sharpe Proportion over 1.00 (Dowd, 2000). Geltner, (2003) moreover notices that in connection to assessing Sharpe proportion of a portfolio there ought to moreover be IRR related with portfolio execution degree. In its peer group have an average Sharpe Ratio above 1.00 MFoxCNBC, (2020); Geltner, (2003) also mentions that in relation to evaluating Sharpe ratio of a portfolio there should also be IRR associated with portfolio performance measure.

\section{Importance of Classifying Assets for Selection -} Security selection is the process of identifying individual securities within a certain asset class that will make up the portfolio (Nanda et al., 2010; Momeni et $a l ., 2010)$. The process of making effective selections is guided through the process of making effective selections for assets based on their financial performance measures (Khan et al., 2020; Qudah et al., 2000). Our theoretical frame work thus addresses to confirm following activities in order to address the solution process effectively.

\section{Process 1:}

1) Random selection of assets from various online sources like -
a) www.fknol.com
b) www.fools.com
c) www.investors.com
d) www.yahoo.finance.com

2) Selecting a specific time period for those selected assets.

3) Collect the asset prices for those selected dates

UniversePG I www.universepg.com
4) Apply those assets in a PyPortfolioOpt Optimizer and get a result in terms of Sharpe Ratio \& Portfolio Return.

\section{Process 2:}

1) Collect EPS \& Current Ratio for those randomly selected assets

2) Apply K Means Clustering in order to segregate the selected assets into the desirable asset class

\section{Feature Settings:}

EPS: Greater Than 1

Current Ratio: Greater than 1 and less than 2

3) Applying the Selected asset classes through PyPortfolioOptfor Portfolio Optimization process.

4) Evaluating the result of Newly Selected Portfolio with Randomized Portfolio in-terms portfolio performance through Sharpe ratio and Portfolio return.

\section{METHODOLOGY:}

In order to understand the true potential of portfolio management, the selected time period for performance is considered as January \& February 2020 (MFoxCNBC, 2020). In the process of application, K Means Clustering the primary task would be associated with feature selections by which an asset could be classified as good investment property from another asset which is not. Feature selection properties have been demonstrated throughout as

\section{EPS >> As High as Possible \\ $1.0<$ Current Ratio $<=2.0$}

In the position of Given set of observations between xi and yi, where the observations are d-dimensional real vector, the target of $\mathrm{K}$ Means clustering is to segregate the $\mathrm{n}$ observations in $\mathrm{K}$ sets. Formally the main target is to generate:

The minimum point of difference from the existing true reference point of $\mathrm{i}(1,2, \ldots, \mathrm{N}) \mathrm{C}$ where 1,2 , ......, $\mathrm{N}$ are all the observations for variables.

Here, $\mathrm{Xi}$ is representing EPS

Yi is representing Current Ratio

Hence K Means Clustering would truly find the actual difference of points with best performing EPS \& Current Ratio values in order to segregate the best stocks from the worst stocks for portfolio selection.

$$
\operatorname{Arg}-\operatorname{Min}\left(\operatorname{SQRT}\|x i-U x\|^{\wedge} 2+\|y i-U y\|^{\wedge}\right. \text { 2)= }
$$




\section{Minimum Point of Difference}

Ux are the average points for EPS

Uy are the average points for Current Ratio

Process 2: Secondary Check:

Using $\mathrm{K}$ Nearest Neighbor Clustering, this paper would initiate the task to initially select the effective EPS and Current ratio value and select the assets only with the minimum difference attribute.

Hence, the best asset choice will be -

\section{$\operatorname{Min}(\operatorname{ABS}(K(X i, Y i)-K(\operatorname{Mod} X, \operatorname{Mod} Y)))$}

ABS refers to absolute value

$\mathrm{K}$ (xi, yi) refers the respective weighted attribute of EPS and Current ratio of Assets

K (Mod X, Mod Y) determines the ultimate quality attribute of best EPS and Current Ratio.

$\mathrm{K}$ refers to the values of variables

Assets will be the list of all assets; those are randomly selected for portfolio with their quality attributes of EPS and Current ratio

Hence the Algorithm would be as such

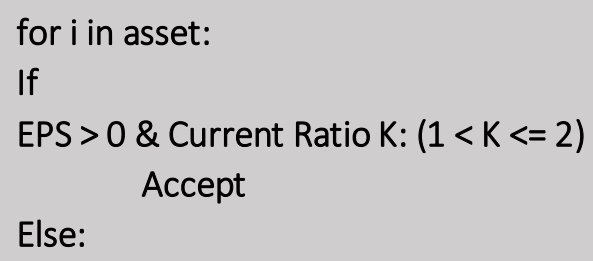

Final Step: Apply the selected group of assets into the portfolio. After making the selection we would apply them using the portfolio return formula:

Expected Return $=$ WAi $\times$ Rai + +WAnXRAn

Where;

WAi $=$ Weight of security Ai

$\mathrm{RAi}=$ Expected return of security Ai

WAn $=$ Weight of security An

RAn $=$ Expected return of security

Here $\mathrm{i}$ refers to all the assets which are present in the portfolio from $1,2, \ldots . n$

\section{RESULTS AND FINDINGS:}

In order to make the portfolio optimization process effective, the Stock suggestion taken using theoretical framework (Nanda et al, 2010; Momeni et al., 2015) we have taken several stocks as suggestions without the boundary of their effective EPS and Current Ratio.
Under the effective suggestion we have considered two months ratio price as the benchmarks for portfolio optimization test process.

As PyPortfolioOpt mentions everything under the perspective of yearly gains hence the overall returns are forecasted as annualized returns. But this research paper has brought how pre-evaluated assets can make tremendous developments in Portfolio gains as the benchmark is yearly return. In accordance to the suggestions of various online medium it's found that various assets like popular ones are only suggested as the best contributor of the portfolio which as a whole are good contributors for the portfolio but for short term gains various different assets should be suggested in accordance to their financial ratios.

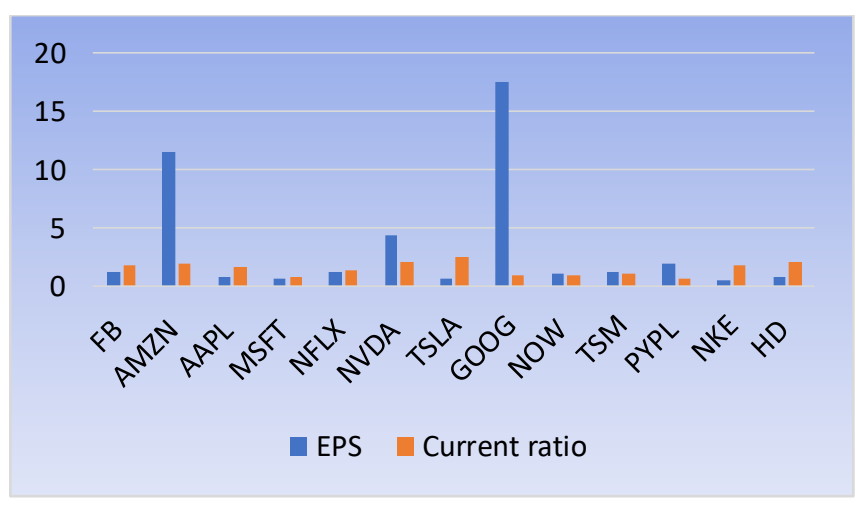

The assets which were selected for random methods are seen to have major problems with Current ratio and some have extremely high EPS while some have extremely low EPS. The Overall return and risk variance for the randomized portfolio is found out through PyPortfolioOpt in order to understand the Portfolio's return.

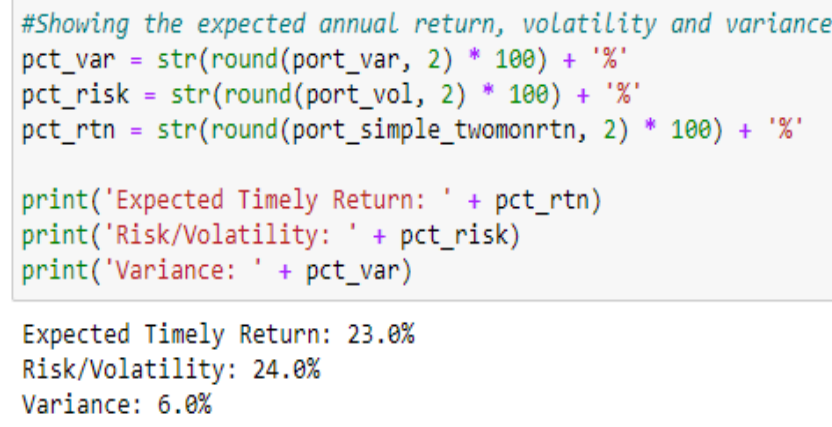

In the process of making selection of assets where the relevant features are only selected are demonstrated for the preferential portfolio. The selected assets are described with their specific EPS and Current Ratio here: 


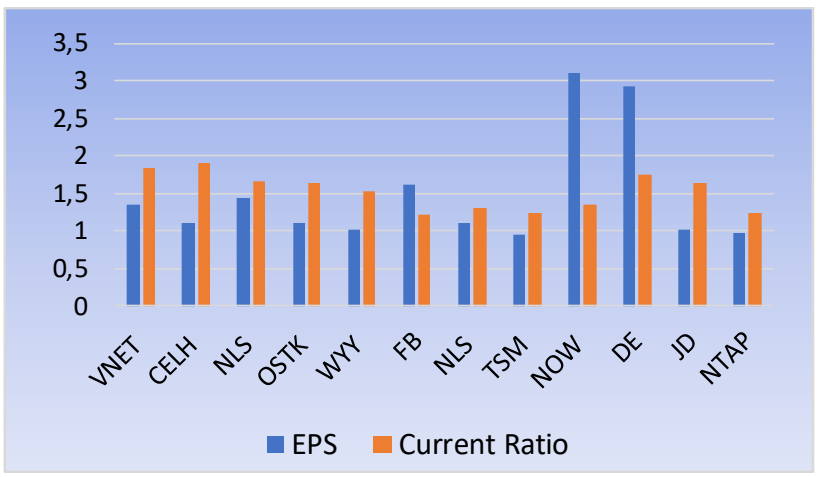

Here the entire assets were selected using K-Nearest Neighbor algorithm and later on tested through K Means Clustering Method for selection of absolutely same assets for portfolio optimization. Using the PyPortfolioOpt it's seen that the above-mentioned assets make the overall return and risk variance:

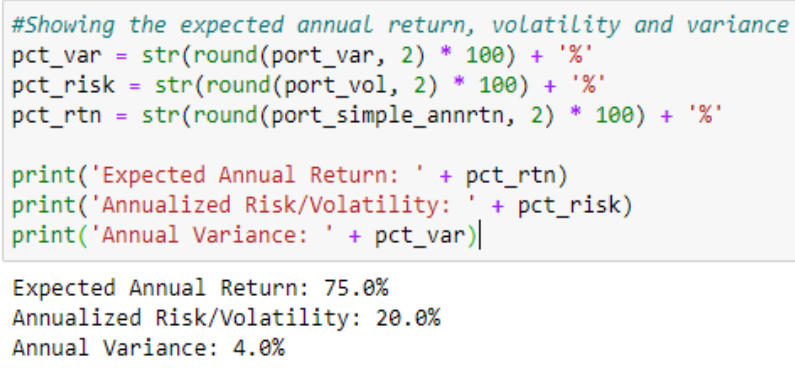

The portfolio optimization method also has suggested which two assets were the biggest contributor of financial portfolio. The discrete allocation process has made the total numbers of assets contribution process much more effective and efficient through outPyPortfolioOpt process.

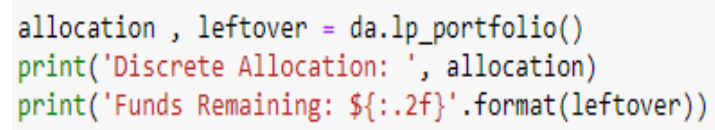

It's seen that the portfolio analysis process was highly capable of making accurate suggestions regarding the asset selection but failed to make exact predictions regarding number of asset allocations or weight distributions.

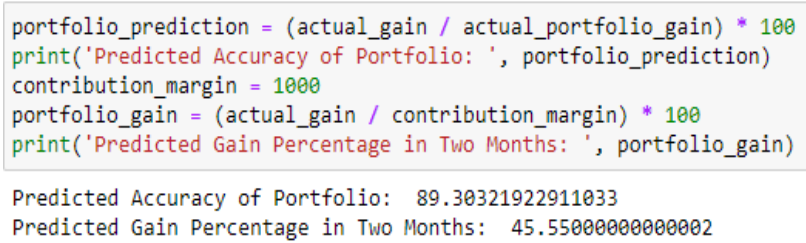

It's found that the overall portfolio created through effective selection of assets are highly capable of performing and they are nearly $89 \%$ similar in reference to actual or best performing portfolio with an effective gain of $45 \%$ in an average with an effective contribution margin of $\$ 1000$ as the initial investment amount.

\section{CONCLUSION:}

In our research process we have identified, how stocks in NYSE could be used effectively through classification-based Machine Learning processes. Also, it's seen that return and risk measure calculations are always much better under biased and favorable circumstances rather than randomized circumstances. It's seen that effective selection of assets always bring better profits as random portfolio made a annualized return of $23 \%$ whereas assets with favorable financial ratios made $75 \%$ overall annualized return. The overall risk measure of the randomized portfolio was less than the return whereas for selected asset portfolio it's seen to have a very low risk in comparison to its return. Finally, the annualized variance of high return portfolio is lower than randomized portfolio at $4 \%$ and $6 \%$ respectively. Our overall portfolio management process didn't make use of any initiation of time series forecasting method that can show if the selected assets would be able to make a positive and negative gain for the considered period. Although the assets were referred through good suggestion by classification process suggested through financial principles, but if the time series forecasting were not applied then all these assets could have a negative ROI which was not discussed in this paper. This paper was highly focusing towards elaborating the benefit of portfolio construction process and classification-based selection process; hence the major effectivity of time series forecasting was not mentioned in this paper. The secondary data sources were also not highly reliable as there were various other important financial ratios which were not found in the open data sources.

\section{ACKNOWLEDGEMENT:}

This research paper is a contribution effort in order to understand the benefit of financial ratios as a benchmark for classifying important assets. Hence all the related researches are of paramount importance for this paper. Also, various theoretical aspects such as EPS 
ratio and Current Ratio and their suggestions as standard point is referred as benefits understanding for asset selection for portfolio; so the theoretical aspects need to acknowledge as well for the research paper.

\section{CONFLICTS OF INTEREST:}

The author declared there is no potential conflict of interest to publish it.

\section{REFERENCES:}

1) Azam MS, Rahman A, and Ahmed MT. (2020). Prediction of liver diseases by using few machine learning based approaches, Aust. J. Eng. Innov. Technol., 2(5), 85-90. https://doi.org/10.34104/ajeit.020.085090

2) Barnes, (1987). The Analysis and Use of Financial Ratios: A Review. Journal of Business Finance \& Accounting, 14(4); 0306-686X.

3) Baumann, P., \& Trautmann, N. (2012). Portfolio-optimization models for small investors. Mathematical Methods of Operations Research, 77(3), 345-356.

https://doi.org/10.1007/s00186-012-0408-3

4) Bauman, W Scott; Miller, Robert E. (1997). Investor expectations and the performance of value stocks versus growth stocks. Journal of Portfolio Management; London, 23(3): 57-68.

5) Bodnar, T., \& Zabolotskyy, T. (2016). How risky is the optimal portfolio which maximizes the Sharpe ratio? AStA Advances in Statistical Analysis, 101(1), 1-28. https://doi.org/10.1007/s10182-016-0270-3

6) Brinson, G. P., Hood, L. R., \& Beebower, G. L. (1986). Determinants of Portfolio Performance. Financial Analysts Journal, 42(4), 3944. https://doi.org/10.2469/faj.v42.n4.39

7) Chen, K. H., \& Shimerda, T. A. (1981). An Empirical Analysis of Useful Financial Ratios. Financial Management, 10(1), 51. https://doi.org/10.2307/3665113

8) Dowd, K. (2000). Adjusting for risk: International Review of Economics \& Finance, 9(3), 209-222. https://doi.org/10.1016/s1059-0560(00)00063-0

9) Eljelly, A. M. A. (2004). Liquidity - profitability tradeoff: An empirical investigation in an emerging market. International Journal of Commerce and Management, 14(2), 48-61. https://doi.org/10.1108/10569210480000179

10) Fresh Books, (2020, July 20). What Is a Good Liquidity Ratio? Fresh Books.

https://www.freshbooks.com/hub/accounting/goo d-liquidity-ratio\#:\%7E:text=Current\%20Ratio,-The \%20current $\% 20$ ratio\&text=The $\% 20$ current $\%$ 20liabilities \%20refer\%20to,liabilities \%20to\%20 covers $\% 20$ its $\% 20$ debts.

11) Geltner, D. (2003). IRR-Based Property-Level Performance Attribution. The Journal of Portfolio Management, 29(5), 138-151. https://doi.org/10.3905/jpm.2003.319915

12) Idzorek, T. (2007). A step-by-step guide to the Black-Litterman model. Forecasting Expected Returns in the Financial Markets, 17-38. https://doi.org/10.1016/b978-075068321-0.5000 $\underline{3-0}$

13) Jordan, C. E., Clark, S. J., \& Smith, W. R. (2007). Should Earnings per Share (EPS) Be taught as a Means of Comparing Intercompany Performance? Journal of Education for Business, 82(6), 343-348.

https://doi.org/10.3200/joeb.82.6.343-348

14) Khan, K. I., Naqvi, S. M. W. A., Ghafoor, M. M., \& Akash, R. S. I. (2020). Sustainable Portfolio Optimization with Higher-Order Moments of Risk. Sustainability, 12(5), 2006. https://doi.org/10.3390/su12052006

15) Li, B., \& Hoi, S. C. H. (2014). Online portfolio selection. ACM Computing Surveys, 46(3), 1-36. https://doi.org/10.1145/2512962

16) Lin, F., Liang, D., \& Chen, E. (2011). Financial ratio selection for business crisis prediction. Expert Systems with Applications, 38(12), 15094-15102.

https://doi.org/10.1016/j.eswa.2011.05.035

17) López de Prado, M. (2016). Building Diversified Portfolios that Outperform out of Sample. The J. of Portfolio Management, 42(4), 5969. https://doi.org/10.3905/jpm.2016.42.4.059

18) Mamun AMA, Islam T, Siam MMS, and Kabir ME. (2020). Development of smart librarian with the virtual assistant (PRIMO), Aust. J. Eng. Innov. Technol., 2(4), 54-65. https://doi.org/10.34104/ajeit.020.054065 
19) MFoxCNBC, (2020). Coronavirus crisis is causing financial stress for nearly 9 in 10 Americans, CNBC. Available online at https://www.cnbc.com/2020/04/16/coronaviruscrisis-causing-financial-stress-for-near-9-in-10americans.html

20) Momeni M, Mohseni M, Soofi M. (2015). Clustering Stock Market Companies via KMeans Algorithm Kuwait Chapter of Arabian, Journal of Business and Management Review, 4(5); January. 2015.

21) Nanda, S. R., Mahanty, B., \& Tiwari, M. K. (2010). Clustering Indian stock market data for portfolio management. Expert Systems with Applications, 37(12), 8793-8798. https://doi.org/10.1016/j.eswa.2010.06.026

22) Qudah A.A.A \& Al-Afeel M.A.M. (2015). The Relationship between the Investment in Current Assets and Profitability \& Liquidity, Journal of Finance and Investment Analysis, 4(4), 11-22.
23) Rashidi, P., and Analoui, M. (2007). Modified k-means algorithm for clustering stock market companies, $1^{\text {st }}$ Iran Data Mining Conference 201-21, Tehran: Amir Kabir University

24) Robert A. M. (2021), PyPortfolioOpt: portfolio optimization in Python, The Journal of Open Source Software, Available online at https://doi.org/10.21105/joss.03066

25) Saito-Chung, D. (2021). Why The EPS Rating Is One Key To Picking The Best Stocks. Investor's Business Daily, online at https://www.investors.com/how-to-invest/invest ors-corner/eps-rating-is-key-to-picking-great-sto cks/

26) Zhou, X. Y. (2000). Continuous-Time MeanVariance Portfolio Selection: A Stochastic LQ Framework. Applied Mathematics and Optimization, 42(1), 19-33. https://doi.org/10.1007/s002450010003

Citation: Sami HM. (2021). Portfolio construction using financial ratio indicators and classification through machine learning, Int. J. Manag. Account. 3(4), 83-90. https://doi.org/10.34104/ijma.021.083090@@ () 